\title{
Road Dust Emission Spatial Characteristics of Shijiazhuang in 2014 Spring
}

\author{
Jieying Xiao*, Juan Liu, Wenxia Zhao, Shuo Guo, Sai An, Hui Kang, Tianlin \\ Yang
}

School of Environmental Science and Engineering, Hebei University of Science and Technology, Shijiazhuang 050018, China

18333195615@163.com

Keywords: Road silt loading; Road dust emission; Road information extraction

\begin{abstract}
City road dust was one of the main sources of $\mathrm{PM}_{10}$. In this paper, roads were classified into four types: expressway, trunk road, secondary trunk road and branch road. Dust samples were collected from 17 representative roads of Shijiazhuang city, and were analyzed by laser particle size analyzer. And high-resolution vector quantization images of roads were extracted by Google Earth with Photoshop, GlobalMapper and ArcGIS. On the basis, road silt loading of Shijiazhuang in 2014 spring were obtained. The results showed that D50 (Median diameter) of the road dust ranged from 27.7-63.6 $\mu \mathrm{m}$. Average silt loading of different road types were $6.2-13.4 \mathrm{~g} \cdot \mathrm{m}^{-2}$, and the sequence was branch road $>$ secondary trunk road $>$ expressway $>$ trunk road.
\end{abstract}

\section{Introduction}

In recent years, with the rapid development of economy, regional environmental air pollution has been more and more serious in China. The haze weather has mainly been caused by particulate matter, especially $\mathrm{PM}_{10}$ and $\mathrm{PM}_{2.5}$ [1]. The particulate matter is not only harmful to environment and climate, but also to human health [2]. The haze weather frequently occurs in Shijiazhuang. The air source apportionment results here show that road dust has contributed $37.5 \%$ to $\mathrm{PM}_{10}$ in 2013 [3].

The road information extraction is the foundation. With the development of computer technology, PhotoShop, ArcGIS, MapInfo, GlobalMapper, can be used for information extraction [4]. The combination methods of computer software for road information extraction have the advantages of few steps, a high accuracy and wide application.

In this paper, Shijiazhuang was the research area, road information was extracted by Google Earth, PhotoShop, GlobalMapper and ArcGIS. Road silt loading in 2014 spring was established. The results can provide a certain basic reference for preventing and controlling road dust pollution of Shijiazhuang.

\section{Experimental methodology}

The dust samples of road were collected from 1st Feb to 1st Apr, 2014. 17 representative roads were chosen as research objects. 54 sampling points were set up on them. The 17 roads were: South Second Ring Road, Huai'an Road, Heping Road, Zhongshan Road, Yuhua Road, Jianhua Street, Zhonghua Street, Tiyu Street, Jianshe Street,Tanan Road, Shiluan Road, Huitong Road, Youyi Street, Donggang Road, Huaizhong Road, Fanxi Road and Sizhong Road.

According to the above method, 54 road dust samples were collected. Then they were taken back to lab and the large impurities in them were picked out. After the natural air-dry, 54 samples were respectively weighted and put in the sealed bags. Next the samples were pretreated as follows: Firstly one sample was screened by the 20 meshes standard sieve, next the undersize fraction was screened by the 200 meshes standard sieve. And the oversize fraction of 20 meshes sieve and the oversize fraction of 200 meshes sieve were respectively weighted by the analytical balance. Then the undersize fraction of 200 meshes sieve was stored in a sealing bag and labeled. 54 samples were sieved in turn. The dust samples from the same road were mixed as one mixed sample. The data of 
the sample weight was used to calculate road silt loading. The mixed samples were used for determination of the granularity.

The granularity of samples were measured by the BT-9300S laser particle size analyzer. The determination process was as follows, firstly, the laser particle size analyzer and the external circulation system were turned on and the deionized water was put into the external circulation system. After one minute, the background value of the analyzer was measured. Secondly, a mixed sample was put into the external circulation system and mixed with the deionized water to form a stable system. Then ultrasonic vibration was opened for two minutes. Until the continuous testing results were shown in the analyzer, the stable data result was chosen as the granularity of the sample.

Based on the combination of Google Earth Pro V7.1.1 polygon tool and computer drawing softwares, high-resolution images of the roads were extracted. Next PhotoShop was used to make the road tracked and mapped. Then the format of the image was transformed in GlobalMapper. At the last, the road area was quantized in ArcGIS.

\section{Results}

In table 1, the roads were classified into four types of expressway, trunk road, secondary trunk road and branch road by road wide. In table 2, the D50 (Median diameter) of the road dust ranged from $27.7 \mu \mathrm{m}$ to $63.6 \mu \mathrm{m}$. The percentage of TSP in the road dust accounted for more than $85 \%$. The percentage of $\mathrm{PM}_{10}$ in the road dust ranged from $2.1 \%$ to $25.6 \%$. And the percentage of $\mathrm{PM}_{10 \_}$of the trunk road dust was the most, which of the average value is $12.3 \%$.

Table1 Road wide of the different road types

\begin{tabular}{|c|c|c|c|c|c|}
\hline Road types & expressway & trunk road & \multicolumn{2}{|c|}{ secondary trunk road } & branch road \\
\hline Road wide (m) & $>40$ & $30 \sim 40$ & \multicolumn{2}{|c|}{$20 \sim 24$} & $14 \sim 18$ \\
\hline & \multicolumn{5}{|c|}{ Table 2 Determination results of the road dust granularity } \\
\hline & Road types & Road No. & TSP (\%) & $\mathrm{PM}_{10}(\%)$ & $\mathrm{D}_{50}(\mu \mathrm{m})$ \\
\hline & \multirow[t]{2}{*}{ expressway } & 1 & 89.2 & 7.4 & 60.6 \\
\hline & & 2 & 100.0 & 20.2 & 31.1 \\
\hline & \multirow[t]{7}{*}{ trunk road } & 3 & 85.5 & 2.1 & 64.1 \\
\hline & & 4 & 100.0 & 25.6 & 27.7 \\
\hline & & 5 & 95.5 & 7.6 & 48.7 \\
\hline & & 6 & 97.1 & 9.8 & 45.9 \\
\hline & & 7 & 99.7 & 22.9 & 34.9 \\
\hline & & 8 & 85.8 & 4.9 & 63.6 \\
\hline & & 9 & 99.7 & 19.8 & 34.7 \\
\hline & \multirow[t]{4}{*}{ secondary trunk road } & 10 & 86.1 & 7.0 & 63.0 \\
\hline & & 11 & 94.2 & 8.2 & 50.9 \\
\hline & & 12 & 96.3 & 8.4 & 46.5 \\
\hline & & 13 & 94.4 & 7.7 & 51.4 \\
\hline & \multirow[t]{4}{*}{ branch road } & 14 & 90.4 & 2.2 & 56.7 \\
\hline & & 15 & 94.8 & 3.7 & 53.1 \\
\hline & & 16 & 93.8 & 7.0 & 52.0 \\
\hline & & 17 & 95.0 & 6.9 & 49.0 \\
\hline
\end{tabular}


Table 2 Road information and road silt loading

\begin{tabular}{|c|c|c|c|c|c|}
\hline Road Types & Road No. & $\begin{array}{l}\text { Road length } \\
(\mathrm{km})\end{array}$ & $\begin{array}{c}\text { Traffic flow } \\
\left(\mathrm{h}^{-1}\right)\end{array}$ & $\begin{array}{c}\mathrm{sL} \\
\left(\mathrm{g} \mathrm{m}^{-2}\right)\end{array}$ & $\begin{array}{c}\text { Average sL } \\
\left(\mathrm{g} \mathrm{m}^{-2}\right)\end{array}$ \\
\hline \multirow[t]{2}{*}{ expressway } & 1 & 10.5 & 4560 & 6.2 & 6.9 \\
\hline & 2 & 11.5 & 5354 & 7.5 & \\
\hline \multirow[t]{7}{*}{ trunk road } & 3 & 11.3 & 1370 & 3.8 & 6.2 \\
\hline & 4 & 11.7 & 1180 & 5.4 & \\
\hline & 5 & 11.6 & 3657 & 15.2 & \\
\hline & 6 & 10.4 & 2759 & 10.0 & \\
\hline & 7 & 10.6 & 1867 & 3.5 & \\
\hline & 8 & 10.4 & 3499 & 2.1 & \\
\hline & 9 & 10.3 & 3047 & 3.8 & \\
\hline secondary trunk & 10 & 7.6 & 821 & 15.6 & 11.8 \\
\hline \multirow[t]{3}{*}{ road } & 11 & 1.9 & 1248 & 9.4 & \\
\hline & 12 & 2.9 & 1820 & 17.6 & \\
\hline & 13 & 9.2 & 1838 & 4.6 & \\
\hline \multirow[t]{4}{*}{ branch road } & 14 & 5.7 & 890 & 14.6 & 13.4 \\
\hline & 15 & 7.7 & 805 & 12.9 & \\
\hline & 16 & 1.1 & 1176 & 1.8 & \\
\hline & 17 & 0.8 & 980 & 24.2 & \\
\hline
\end{tabular}

In Table 2, the silt loading of the different roads in Shijiazhuang were $1.8-24.2 \mathrm{~g} \cdot \mathrm{m}^{-2}$, the maximum value appeared on Sizhong Road, while the minimum appeared on Fanxi Road. The average silt loading of the different road types in Shijiazhuang was $6.2-13.4 \mathrm{~g} \cdot \mathrm{m}^{-2}$, it was much higher than that of Beijing city $\left(0.17-2.6 \mathrm{~g} \cdot \mathrm{m}^{-2}\right)$ [5]. Obviously, the roads of Shijiazhuang were dirtier. The reasons were that there were more high pollution industries in Shijiazhuang, for example, cement, steel and plate glass, moreover, there were more construction sites without suppressing dust measures. The average silt loading of the different road types was branch road $>$ secondary trunk road $>$ expressway $>$ trunk road. Because branch road had the characteristics of less cleaning and less traffic flow, while trunk road or expressway was with more traffic flow and more cleaning times. The road silt can easily be brought up with the vehicle to form fugitive dust into the air. So the effect of traffic flow on the road silt loading was the most important.

\section{Conclusion}

In this study, the road silt loading of Shijiazhuang in 2014 spring was obtained, and the road information was extracted by the combination methods of Google Earth, PhotoShop, GlobalMapper and ArcGIS. On the basis, the road dust emission spatial characteristics were established.

(1) The D50 (Median diameter) of the road dust ranged from $27.7 \mu \mathrm{m}$ to $63.6 \mu \mathrm{m}$. The percentage of TSP in the road dust accounted for more than $90 \%$. The percentage of $\mathrm{PM}_{10}$ ranged from $2.1 \%$ to $25.6 \%$. The percentage of $\mathrm{PM}_{2.5}$ was very low.

(2) The silt loading of the different roads in Shijiazhuang was $1.8-24.2 \mathrm{~g} \cdot \mathrm{m}^{-2}$. The average silt loading of the different road types in Shijiazhuang was $6.2-13.4 \mathrm{~g} \cdot \mathrm{m}^{-2}$. The average silt loading was in sequence of branch road $>$ secondary trunk road $>$ expressway $>$ trunk road.

\section{Acknowledgments}

This work was financially supported by National Environmental Protection Public Benefit Research Fund (201409004), Hebei Province Science and Technology Support Program (14273712D), Higher School Science and Technology Research Projects of Hebei Province (ZD2014101) and Five Big Platform Open Fund of Hebei University of Science and Technology 
(2014-11).

\section{Reference}

[1] Wang J., Hu Z.M., Chen Y.Y., Chen Z.L., Xu S.Y. Contamination characteristics and possible sources of PM10 and PM2.5 in different functional areas of Shanghai, China[J]. Atmospheric Environment 68 (2013) 221-229.

[2] Janssen N.A.H., Fischer P., Marra M., Ameling C., Cassee F.R. Short-term effects of PM2.5, PM10 and PM2.5-10 on daily mortality in the Netherlands[J]. Science of the Total Environment 463-464 (2013) 20-26.

[3] Wu W.J., Zhao S.Q., Zhu C., Jiang J.L. A comparative study of urban expansion in Beijing, Tianjin and Shijiazhuang over the past three decades[J]. Landscape and Urban Planning 134 (2015) 93-106.

[4] Biswajeet P., Ulrike H., Mahyat S.T., Nikolas P. An easy to use ArcMap based texture analysis program for extraction offlooded areas from TerraSAR-X satellite image[J]. Computers \& Geosciences 63 ( 2014) 33-43.

[5] Fan S.B., Yang L.P., Cheng S.Y. Spatial Distribution of PM10 in Regional Road Environment[J]. Environmental Science \&Technology 34 ( 2011 ) 56- 58. 